\title{
Curación de mucormicosis rinocerebral en un paciente pediátrico con leucemia activa
}

\author{
ALVARO WICKI M., CECILIA BOREL A., MILENA VILLARROEL C. y JOSÉ COFRÉ G.
}

\section{Rhinocerebral mucormycosis healing in a pediatric patient with active leukemia}

A 14 year old leukemic patient acquired a subacute sinusitis with neurological compromise. Rhinocerebral mucormycosis was diagnosed by nasal biopsy and cerebral MR images. Based on his theorical bad prognosis a conservative approach was adopted with functional surgery for sinusitis and a long treatment with amphotericin B deoxycolate ( 8.5 months) totaling a dose of $7.700 \mathrm{mg}$. Acute leukemia chemotherapy was restarted during antifungal therapy and came into oncological remission. After 31 months follow-up the patient is asymptomatic but relapsed of leukemia.

Key words: Mucormycosis; Rhinocerebral; Acute leukemia; Medical treatment.

\section{Introducción}

La mucormicosis, afección esporádica en pediatría, se describe en adultos como una complicación de muy mal pronóstico, atribuible a las magras condiciones inmunitarias del huésped (diabetes mellitus, inmunosupresión), el carácter invasor endovascular de los hongos causales, su fácil ubicación intracraneana, y la escasa disponibilidad de fármacos activos -sólo anfotericina B- sobre los agentes etiológicos. Se presenta un caso de infección extremadamente invasora causado por mucor en un niño con leucemia activa, con resolución favorable pese a no haberse efectuado cirugía radical del foco infeccioso.

\section{Caso clínico}

Paciente varón de 14 años de edad, portador de leucemia linfoblástica aguda (LLA) L1 (clasificación $\mathrm{FAB}$ ), inmunofenotipo común, sin compromiso inicial del SNC, diagnosticada en noviembre de 1999. Inició tratamiento oncológico según el protocolo del Programa Infantil de Dro- gas Antineoplásicas (PINDA), basado a su vez en el protocolo alemán BFM, con buena respuesta a corticoesteroides el día $8^{\circ}$. Se documentó remisión de la leucemia el día 33 de quimioterapia por mielograma y posteriormente, con nuevo mielograma efectuado al término de la fase $\mathrm{M}$. A fines de mayo del 2000 inició la fase II del protocolo, con dexametasona en dosis de $10 \mathrm{mg} / \mathrm{m}^{2} /$ día. Durante la tercera semana de este tratamiento presentó una sinusitis etmoidal, frontal y maxilar derechas (imagen radiológica patológica) e inició tratamiento con axetil cefuroxima. En los días siguientes percibió hipoestesia en la región malar, labial superior y palatina derechas, y luego fiebre, apareciendo un aumento de volumen fronto parietal y una parálisis facial periférica ipsilaterales, por lo que fue hospitalizado para mayor estudio. Inicialmente tenía PCR $163 \mathrm{mg} / \mathrm{l}$, hematocrito $27 \%$, hemoglobina $8,9 \mathrm{gr} / \mathrm{dl}$, recuento de leucocitos $1000 / \mathrm{mm}^{3},\left(\right.$ RAN 200 céls $/ \mathrm{mm}^{3}$ ) y plaquetas $67.000 / \mathrm{mm}^{3}$. Los diagnósticos de ingreso fueron LLA en quimioterapia, neutropenia febril, pansinusitis aguda, parálisis facial periférica derecha ¿secundaria a vincristina? Se inició terapia asociada con cefotaxima + cloxacilina. La evaluación neurológica describió conciencia conserva-

Hospital Luis Calvo Mackenna:

Residente Neurología (AWM), Servicio de Cirugía (CBA), Unidad de Oncología (MVC), Unidad de Infectología (JCG).

Recibido: 22 agosto 2003

Aceptado: 1 octubre 2003 
da, potencia y tono muscular normales, reflejos osteotendíneos abolidos y compromiso de los siguientes nervios craneanos del lado derecho: hipoestesia del $\mathrm{V}^{\mathrm{o}}$, parálisis periférica del VII, paresia del IX y XII. Se postuló la existencia de una infiltración leucémica del tronco cerebral y/o nervios periféricos. La TAC de cavidades paranasales reveló extenso velamiento de senos frontal, etmoidal, esfenoidal y maxilar derecho. La TAC cerebral no demostró imágenes de abscesos cerebrales. Al agregarse al tercer día un síndrome de Claude Bernard Horner derecho se solicitó una RM cerebral que reveló imagen de posible cerebritis frontal derecha como foco contiguo al seno etmoidal, vasculitis de la carótida derecha y mastoiditis ipsilateral (Figura 1). Se planteó la posibilidad de una mucormicosis rinocraneana, basados en el compromiso neurológico y el aspecto de la mucosa nasal, que fuera descrita por el otorrinólogo como necrótica e isquémica. Una biopsia de la mucosa nasal efectuada al tercer día fue informada como: "fragmentos de tejido fibrovascular necrótico que incluyen elementos micóticos del tipo mucor (hifas anchas no septadas en ángulo recto)", informe que fue corroborado en otro centro de diagnóstico histopatológico. No se efectuó cultivo micológico del tejido biopsiado. Se inició tratamiento con anfotericina B deoxicolato en dosis crecientes hasta llegar a $1,5 \mathrm{mg} / \mathrm{kg} /$ día $(90 \mathrm{mg} /$ día $)$. Considerando el habitual sombrío pronóstico de esta enfermedad, se optó por limitar el tratamiento quirúrgico a una cirugía endoscópica funcional etmoidectomía, anterior y posterior, esfenoido-

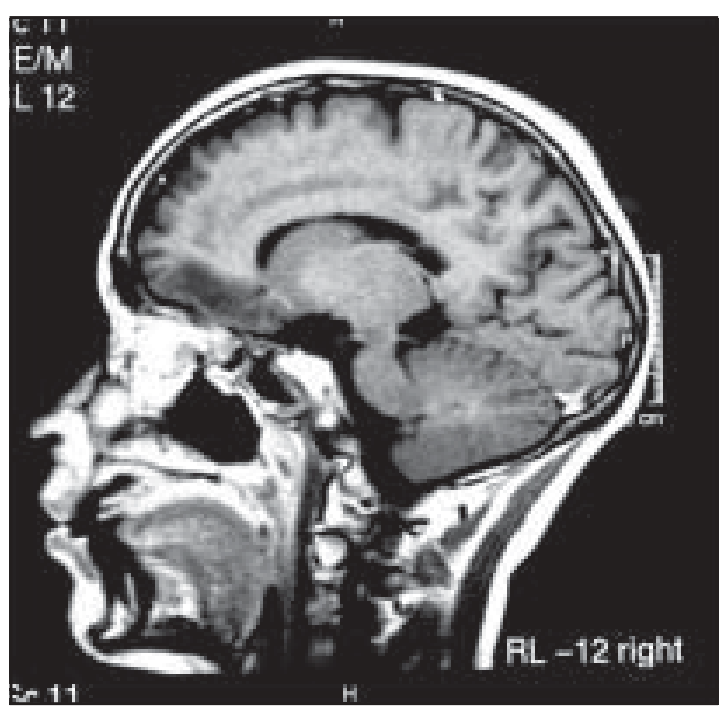

Figura 1. Se aprecia sinusitis etmoidal y cerebritis frontal incipiente. tomía, resección de pared medial de seno maxilar derecho, resección de cornetes medio e inferior, la que fue llevada a cabo al día 6 de ingresado. Pese a documentarse la infección fúngica, continuó en tratamiento antibacteriano con cefotaxima + vancomicina y se adicionó sucesivamente ciprofloxacina y metronidazol.

Al undécimo día de evolución se detectó paresia del $\mathrm{VI}^{\mathrm{o}}$ nervio craneano y signo de Babinsky a izquierda, sospechándose la formación de un absceso cerebral. Una nueva RM fue informada como: "proceso inflamatorio rinosinusal maxilar y etmoidoesfenoidal derecho que se extiende hacia cavidad craneana donde forma absceso frontal. Mastoiditis derecha" (Figura 2). Evaluado nuevamente por neurocirujano se difirió su eventual drenaje. Un mielograma efectuado al día $18^{\circ}$ de hospitalización constató la remisión persistente de la leucemia. En coincidencia con la introducción de la anfotericina B, se asistió a la elevación de creatininemia hasta 2,65 mg/dl, bilirrubinemia total de $1,96 \mathrm{mg} / \mathrm{dl}$, bilirrubinemia conjugada de $1,26 \mathrm{mg} / \mathrm{dl}$, fosfatasas alcalinas 540 UI, GOT $186 \mathrm{mg} / \mathrm{dl}$ y GPT $146 \mathrm{mg} / \mathrm{dl}$, hallazgos que fueron interpretados como nefro $\mathrm{y}$ hepatotoxicidad por anfotericina $\mathrm{B}$; entonces se redujo la dosis de anfotericina $\mathrm{B}$ a $75 \mathrm{mg} \mathrm{c} / 48$ horas y posteriormente a $50 \mathrm{mg} \mathrm{c} / 48$ horas con lo cual los parámetros de laboratorio mejoraron paulatinamente, cesó la hepatitis colestásica pero persistió una creatininemia sobre $1,2 \mathrm{mg} / \mathrm{dl}$. La función renal se normalizó solamente una vez que se suspendió el tratamiento antifúngico.

Al día $35^{\circ}$ de enfermedad se repitió la $\mathrm{RM}$

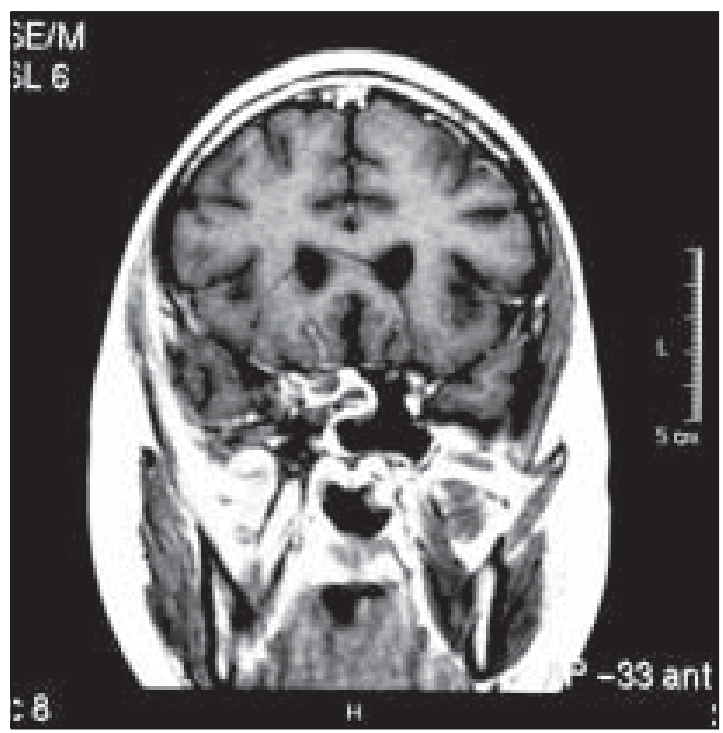

Figura 2. Se aprecia mastoiditis absceso frontal encapsulado. 
cerebral que sólo demostró mayor edema perilesional frontal. Se discutió ampliamente someter al paciente a una cirugía radical craneofacial o limitar el tratamiento al manejo no quirúrgico, en consideración a su probable mal pronóstico, y a la espera de evaluar la respuesta a anfotericina B. Una nueva TAC de cerebro efectuada a los 50 días de tratamiento demostró reducción del absceso frontal en un $20 \%$ por lo que el conjunto de especialistas descartó efectuar la cirugía. Se continuó con anfotericina $50 \mathrm{mg} /$ día en forma intermitente y se reanudó la quimioterapia de mantención con metotrexato y 6 mercaptopurina, a partir del $45^{\circ}$ día de anfotericina. Una nueva RM de cerebro a los 80 días de enfermedad demostró una mayor disminución del tamaño de la lesión frontal (Figura 3). El día $96^{\circ}$ de hospitalización se indicó su alta hospitalaria habiendo recibido 3.655 mg de anfotericina $\mathrm{B}$, para continuar recibiéndola en forma ambulatoria, en un esquema de $50 \mathrm{mg}$ dos veces por semana. Debió se reinternado un mes más tarde por una sepsis estafilocóccica (SAMR), tratada exitosamente con vancomicina durante 21 días. Se suspendió la anfotericina B en marzo del 2001, 3 meses tras haberse efectuado nueva RM de control que mostraba regresión de las lesiones en la base de cráneo y vasculares carotídeas, lo que fuera interpretado como fenómeno residual inactivo. Completó 8 1/2 meses de tratamiento con anfotericina y una dosis acumulada aproximada de $7.700 \mathrm{mg}(\sim 128 \mathrm{mg} / \mathrm{kg})$. En diciembre de 2002 finalizó la quimioterapia (2 años) por su leucemia, con nueva evaluación que comprobó ausencia de enfermedad oncológica. En un control, agosto de 2003, el paciente estaba asintomático y con una discreta paresia facial derecha. En octubre del 2003 el paciente presentó recaída de su leucemia, la que fue atribuida a la aplicación interrumpida de la quimioterapia inicial. En este momento se le efectuó nueva RM cerebral y de cara con imágenes residuales mínimas; la función renal era normal y una biopsia de mucosa sinusal no detectó la presencia de hongos.

\section{Comentario}

- La mucormicosis es una patología inusual en Pediatría. MW Kline del Texas Children's Hospital de E.U.A., reportó en 198514 casos de mucormicosis en Pediatría en el plazo de 30 años, 10 casos en pacientes oncológicos ${ }^{1}$. KL Peterson revisó la experiencia de su grupo, 32 casos en 40 años, con sólo dos casos pediátricos (uno en paciente oncológico) ${ }^{2}$. En nuestro centro hospitalario pese a la magnitud de la

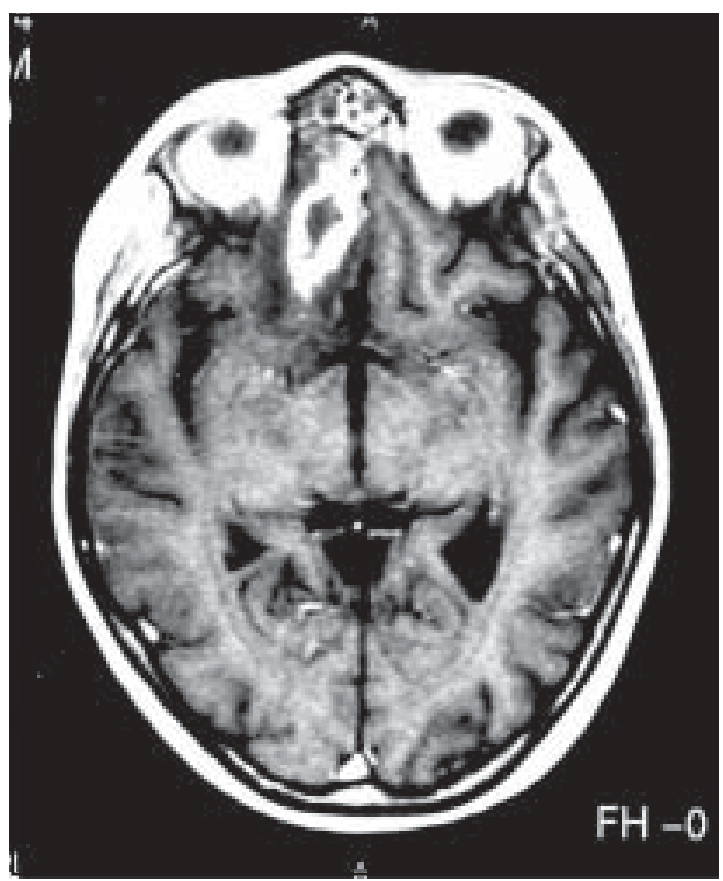

Figura 3. Absceso frontal bien encapsulado y reducción de tamaño.

población de pacientes inmunocompromeridos que atiende (un centenar de nuevos pacientes oncológicos cada año y un número considerable de pacientes sometidos a trasplantes, que incluye al momento de esta publicación: 100 trasplantes renales (desde 1989), 64 trasplantes hepáticos (desde 1996), 48 trasplantes de precursores hematopoyéticos (desde 1999), el presente caso representa el segundo en más de 30 años de revisión.

- El diagnóstico de sinusitis complicada y en definitiva mucormicosis rinocraneana, fue sospechado tempranamente por el compromiso neurológico aparecido en la segunda semana de síntomas, en un paciente que estaba en estrecho control por su afección de base.

- Este diagnóstico se sustentó en el examen histopatológico, considerado el patrón de oro con estos fines ya que el aislamiento de mucor en cultivo de mucosas puede representar una simple colonización ${ }^{3}$. En este caso, en una tinción de biopsia efectuada a una escara necrótica desprendida de la mucosa nasal, se visualizaron de hifas con morfología propia de mucor rodeadas de una reacción inflamatoria, observación que fuera corroborada por un segundo médico patólogo, extrainstitucional y experimentado en esta enfermedad. La falta de cultivo micológico no invalida entonces el diagnóstico etiológico del cuadro -impidió eso sí, 
su mayor caracterización en especie- cuya presentación fue bastante típica: una sinusitis invasora que cursaba comprometiendo los vasos sanguíneos intracraneanos, el tejido cerebral y los nervios craneanos, en una evolución subaguda.

- Nuestra inexperiencia en esta patología dificultó las decisiones quirúrgicas iniciales; se discutió reiteradamente efectuar una cirugía radical de cara, mastoides, base de cráneo e intracraneana, asesorados por otros grupos de especialistas consultados, y según las recomendaciones extraídas en la literatura médica; esta indecisión y tardanza favoreció paradojalmente un tratamiento conservador, efectuándosele sólo una cirugía funcional de sinusitis y posteriormente múltiples curetajes del tejido necrosado, por vía endonasal. Esta actitud más conservadora fue adoptada en consideración a que la cirugía radical que estaba in mente aparecía como extraordinariamente mutilante y tampoco parecía garantizar la recuperación del paciente, toda vez que existía un importante compromiso óseo, de parenquima cerebral y vascular intracraneano, compromiso que además entorpecía el acceso de la anfotericina $\mathrm{B}$ al proceso micótico.

- Otro problema experimentado con este paciente fue la dificultad en definir la curación de la infección y por lo tanto el plazo de tratamiento. En la literatura científica no se especifican plazos de tratamiento y más bien se enfatiza la necesidad de controlar adecuadamente los factores que favorecieron su aparición, v. gr: diabetes, o suspenderlos, v. gr: quimioterapia, corticoterapia, etc. En pacientes adultos se recomienda enterar entre 2,5 y 3,0 gramos como dosis total ${ }^{4}$. En este caso se prolongó la terapia anti fúngica por 8,5 meses, aun en presencia de disfunción renal, y fue suspendida empíricamente en base al seguimiento imagenológico del compromiso intracraneano; finalmente se suspendió la anfotericina $\mathrm{B}$ antes de normalizarse las imágenes de la RM, en consideración a que el edema perilesional había cesado y la colección intracraneana encapsulada había reducido considerablemente su tamaño.

- Es particularmente destacable el éxito terapéutico logrado, contrariamente al pronóstico que estableciera el equipo de médicos tratantes, y a pesar de haberse reanudado la quimioterapia de su leucemia durante la infección activa.

- Si bien se produjo toxicidad renal con deterioro de la filtración glomerular, la protección hidroelectrolítica efectuada antes de cada in- fusión impidió la aparición de toxicidad tubular. $\mathrm{El}$ incremento progresivo de la creatininemia se detuvo una vez que se espació la administración de anfotericina $\mathrm{B}$ a días alternos y luego, a dos dosis semanales, revirtiéndose del todo sólo al suspenderse el medicamento. Pese a este espaciamiento de dosis el paciente continuó mejorando de su infección, lo que reafirmaría el concepto de que anfotericina actúa por acumulación de fármaco y no por dosis diarias. Como único efecto tóxico extrarrenal atribuible al fármaco se detectó una colestasia hepática, que remitió en coincidencia con la reducción de la dosis diaria del fármaco. No fue considerado el empleo de anfotericina liposomal por estar fuera de alcance presupuestario en nuestra institución pues representa un gasto cercano a US 300.00 diarios. Con anfotericina liposomal hay reportes terapéuticos exitosos en mucormicosis atribuidos al uso de mayores dosis diarias de anfotericina: $5-10 \mathrm{mg} / \mathrm{kg}^{5,6}$. Entre los nuevos antifúngicos desarrollados, posaconazol y ravuconazol exhiben in vitro en reportes preliminares actividad sobre Rhizopus con CIM $_{50}$ de 1-2 $\mu \mathrm{g} / \mathrm{ml}$ y esperan ser evaluados clínicamente en esta afección ${ }^{7}$.

- El seguimiento del paciente a 29 meses plazo (marzo 2001-agosto 2003), garantiza plenamente su curación de la complicación infecciosa; sin embargo, tras haber estado en remisión oncológica por más de 3 años, recayó de su enfermedad de base a raíz de recibir una quimioterapia interrumpida en su protocolo original.

- Este paciente deja la enseñanza que, aun cuando la mucormicosis rinocraneana es una entidad de sombrío pronóstico en general si no se erradica precozmente el foco infeccioso, la estrategia más conservadora puede ser una alternativa a la cirugía radical para algunos pacientes pediátricos, evitando importantes secuelas anatómicas, funcionales y psicológicas que implica la cirugía radical, a niños que tienen una larga expectativa de vida.

\section{Resumen}

Un paciente de 14 años, portador de leucemia linfoblástica aguda desarrolló una sinusitis subaguda con manifestaciones neurológicas. Mediante biopsia de mucosa nasal y resonancia magnética cerebral se diagnosticó una mucormicosis rinocerebral y basado en un teórico mal pronóstico se decidió efectuar tratamiento conservador: cirugía funcional de la 
sinusitis y terapia prolongada con anfotericina B deoxicolato completando tras 8,8 meses, $7.700 \mathrm{mg}$ del fármaco. La quimioterapia de la leucemia fue reanudada durante el tratamiento antifúngico alcanzando la remisión oncológica. Tras 31 meses de seguimiento, el paciente está asintomático pero recayó de la leucemia.

\section{Bibliografía}

1.- Kline M W. Mucormycosis in children: review of the literature and report of cases. Pediatr Infect Dis 1985; 4: 672-6.

2.- Peterson K L, Wang M, Canalis R F, Abemayor E. Rhinocerebral mucormycosis: Evolution of the disease and treatment options. Laryngoscope 1997 July; 107 (7): 855-62.

3.- Richardson M D, Shankland G S. Rhizopus, Rhizomucor, Absidia, and other agents of systemic and subcutaneous Zygomycoses. En Murray PR, Baron
EJ, Pfaller MA, Tenover FC, Yolken RH, eds. Manual of Clinical Microbiology, 6th ed. Washington DC, ASM Press 1995; 809-24.

4.- Gilbert D N, Moellering R C, Sande M E. The Sanford Guide to Antimicrobial Therapy. 33th edition. Hyde Park, VT, Antimicrobial Therapy INC. 2003; 77.

5.- Herbrecht R, Letscher-Bru V, Bowden R A et al. Treatment of 21 cases of invasive mucormycosis with amphotericin B colloidal dispersion. Eur J Microbiol Infect Dis 2001; 20: 460-6.

6.- Wali Y A, Lamki A L, Kindi A L et al. Case Report. Successful outcome of invasive nasal sinus zygomycosis in a child with relapsed acute lymphoblastic leukemia due to liposomal amphotericin B. Mycoses 2001; 44; 195-9.

7.- Pfaller M A, Messer S A, Hollis R J, Jones R N and the Sentry Participants Group. Antifungal activities of Posaconazole, Ravuconazole, and Voriconazole compared to those of Itraconazole and Amphotericin B against 239 clinical isolates of Aspergillus spp, and other filamentous fungi: Report from SENTRY Antimicrobial Surveillance Program. Antimicrob Agents Chemother 2002 April; 46 (4): 1032-7.

Correspondencia a:

José Cofré Guerra

E-mail: pepecofre@123.cl 